\title{
TWO TYPES OF ONTOLOGICAL FRAME AND GÖDEL'S ONTOLOGICAL PROOF
}

\author{
SERGIO GALVAN \\ Catholic University of Milan
}

\begin{abstract}
The aim of this essay is twofold. First, it outlines the concept of ontological frame (or structure). Secondly, two models are distinguished on this structure. The first one is connected to Kant's concept of possible object and the second one relates to Leibniz's. Leibniz maintains that the source of possibility is the mere logical consistency of the notions involved, so that possibility coincides with analytical possibility. Kant, instead, argues that consistency is only a necessary component of possibility. According to Kant, something is possible if there is a cause capable of bringing it into existence; to this end consistency alone is not sufficient. Thus, while the Leibnizian notion of consistency is at the root of the concept of analytical possibility, the Kantian notion of possibility is the source of real possibility. This difference plays an important role in the discussion of Gödel's ontological proof, which can be formally interpreted on the ontological frame of the pure perfections. While this proof, under some emendation condition, is conclusive in the context of Leibniz's ontological model, it is not so within the Kantian one. This issue will be the subject of the second part of the present essay.
\end{abstract}

\section{ONTOLOGICAL FRAME $S$}

An ontological structure $S$ is a set of possible worlds correlated and determined according to the objects existing in them. Formally:

$$
S=\langle W, R, U, E, Q\rangle
$$


where:

- $W$ is a set of possible worlds

- $R$ is a total relation over $W$

- $U$ is a universal structure formed by a set $U$ of possible objects characterised by attributes (properties and relations) taken from a set $\mathrm{P}$, i.e. $U=\langle\mathrm{U}, \mathrm{P}\rangle$

- $E$ : is a function from possible worlds to the power set of $U$

- $Q$ is a non empty subset of $W$

\subsection{Possible worlds and accessibility relation: $W$ and $R$}

$W$ is a set of ontologically possible worlds. An ontologically possible world is an analytically possible world. As is well known, an analytically possible world is a simply consistent and maximal set of states of affairs. The relation $R$ of accessibility between worlds is a total relation. It establishes that every world is a possible alternative to every other. The relation $R$ expresses the metaphysical and, hence, unconditional nature of the notion of possibility inherent in the structure that we are presenting. We use the symbols $\mathrm{u}, \mathrm{v}, \mathrm{w}, \ldots$ as variables for worlds.

Of course, the normal definition of modal ontic operators holds:

$$
\begin{aligned}
S \mid=_{\mathrm{u}} \square \alpha & \Leftrightarrow \forall \mathrm{v}\left(\mathrm{u} R \mathrm{v} \Rightarrow S \mid=_{\mathrm{v}} \alpha\right) \\
& \Leftrightarrow \forall \mathrm{v}\left(S \mid==_{\mathrm{v}} \alpha\right) \quad \text { (because the totality of } R \text { ) }
\end{aligned}
$$

and

$$
\begin{aligned}
S \mid={ }_{\mathrm{u}} \nabla \alpha & \Leftrightarrow \exists \mathrm{v}\left(\mathrm{u} R \mathrm{v} \wedge S \mid==_{\mathrm{v}} \alpha\right) \\
& \Leftrightarrow \exists \mathrm{v}\left(S \mid={ }_{\mathrm{v}} \alpha\right) \quad \text { (because the totality of } R \text { ) }
\end{aligned}
$$

\subsection{Universal ontological substructure: $U$}

The universal ontological substructure $U$ is made up of a set $U$ of possible objects characterised by attributes (properties and relations) of a set $\mathrm{P}$ :

$$
U=\langle\mathrm{U}, \mathrm{P}>
$$

- $U$ (objectual domain) is a set of possible objects.

A possible object is an analytically possible object, i.e. an object that necessarily satisfies the only requirement of coherence. The set of analytically possible objects is, in turn, subdivided into two disjoint subsets: the subset of really possible objects and the subset of purely possible objects (simply consistent). This distinction is introduced below. Now it is important to stress two issues. Firstly, that the set $\mathrm{U}$ is the same 
in every world. The reason for this is that the objectual domain is a set of possible objects and these are present (as possible), although not (as actual existent), in all worlds. Secondly, it is worth noting that the objects are individual, i.e. completely determined with respect to all properties. The reason for this is the fact that an object can only exist as complete.

As usual, the elements of $U$ are indicated with the signs $x, y, z, \ldots$ It should be noted that the individual names are intended as rigid designators, that is to say that for any name $\mathrm{x}, \mathrm{x}$ designates the same entity in all possible worlds. In the following, allow me to use some signs of the language as metalinguistic signs. For example, the signs $x, y, z, \ldots$ will be used both as linguistic individual variables and as metalinguistic signs for objects. Similarly, expressions such as $S \mid=_{\mathrm{u}} \nabla \alpha$ and $S \mid=_{\mathrm{u}} \square \alpha$ will often be abbreviated to $\diamond \alpha$ and $\square \alpha$. The context will be sufficient to understand the level of expressions.

- $\mathrm{P}$ is the set of attributes (properties and relations) on $\mathrm{U}$.

Given the modal context, the attributes can be intended both intensionally and extensionally. The intension is given as a function establishing the extension of the attribute at each world. However, the intension of the attribute fixes the same extension in every world. In fact, they are conceived in a rigid way, because the attributes belonging to $\mathrm{P}$ are all essential attributes, in Kantian language real, and the individuals of $\mathrm{U}$ are possible objects, that do not vary for essential attributes but just for the fact that they exist in a world or not.

The attribute of existence will be discussed separately since it is the only attribute considered as non-rigid.

\subsection{Existence Predicate $\mathrm{E}$}

\subsubsection{Difference between essential/real predicates and existence predicate}

The basic idea of the ontological structure that we are presenting is that possible objects are the same in all worlds, only the extension of the existence predicate changes from world to world. As stated above, this is based on the distinction between essential or real (in Kantian terminology) predicates and the existence predicate. A real predicate states how the object is determined (order of sosein). Conversely, the existence predicate states if it is actual in one world or another (order of dasein). Consequently, an object can be actual in one world and non-actual in an alternative possible world, despite being identical with respect to essence. 


\subsubsection{Intension of the predicate $\mathrm{E}$}

As previously stated, it is a fundamental assumption of the semantics of the ontological structure that the objectual domain is constant for all possible worlds. However, the possibilia actualised in each of the possible worlds are not the same. The possibilia actualised in a world are only the possibilia existing in that world, i.e. the possibilia for which the property of existence $\mathrm{E}$ is valid in it. So, the possible denoted by $\mathrm{x}$ is actualised in the world $\mathrm{u}$ if and only if $\mathrm{E}(\mathrm{x})$ is true in $\mathrm{u}$. In formal terms:

$$
S \mid={ }_{\mathrm{u}} \mathrm{E}(\mathrm{x})
$$

This amounts to saying that the extension of $\mathrm{E}$ varies from world to world, i.e. that the intension of $\mathrm{E}$ is the function $E: W \mapsto \wp(\mathrm{U})$ and that this function is not constant. Moreover it meets the requirement of the existence condition:

$$
(\forall \mathrm{u})(\varnothing \neq E(\mathrm{u}) \subset \mathrm{U})
$$

The existence condition ensures that the extension of the predicate of existence is never (in any of the possible worlds) empty. This means that, for every world, at least one possible must be actualised. The rationale of this condition is obvious. A possible world is a possible alternative to the actual world, which could not be if none of the possible objects of the world were existent in it.

\subsection{The set $Q$ of really possible worlds}

The mere consistency of a world does not guarantee that this world is really possible. Real possibility requires, besides consistency, a foundation. It should not be simply based on the pure power of being but on a productive force, a power to make be. This power belongs to the cause of a state of affairs if it is a contingent state of affairs, and to the state itself, as an actual state of affairs, if it is a non-caused, i.e. necessary, state of affairs. For this reason we must distinguish within the set $W$ of all analytically possible worlds the set $Q$ of really possible worlds. The relation between $W$ and $Q$ is expressed by this formula:

$$
\emptyset \neq Q \subseteq W .
$$

AN IMPORTANT QUESTION: Why can we not assume that $W$ is made up of only analytically possible worlds? The answer lies in the non-essentialist nature of the theory of being, formalised in the $S$ structure. In any ontological theory based on the distinction between 
essential predicates and existence, existence cannot be deduced from the essential order of things. Therefore, affirming that ontologically possible (i.e. really possible) worlds are analytically possible amounts to saying that existence is a property that can be banally derived from the essential order of things, in the sense that existence can be attributed to any analytically possible world just because of its essential consistency. Conversely, if existence cannot be reduced to essence - as Thomas said - it must come from outside. So, the fact that a specific possible world has been or could be realised cannot be deduced from its essential structure. Therefore, we cannot determine a priori (ex essentia) which worlds are really possible. We can only experience the existence of the actual world and we may consider the real possibility of other ones since the necessary conditions are met in the actual world for their creation, or there are traces of their existence. Anyway, we do not have logically sufficient reasons to equate the set of analytically possible worlds with the set of really possible worlds.

We can, at this point, introduce some new definitions:

\subsection{Definitions}

Definition 1: Existence in a really possible world (Real existence)

Let $\mathrm{Q}$ be a new propositional constant describing the real accessibility of the world in which it is true. In formal terms:

$$
S \mid={ }_{\mathrm{u}} \mathrm{Q} \Leftrightarrow \mathrm{u} \in \mathrm{Q}
$$

Then we can introduce the new predicate $\mathrm{E}^{\star}$ of existence in a really possible world (real existence):

$$
\mathrm{E}^{\star}(\mathrm{x}) \Leftrightarrow \mathrm{Q} \wedge \mathrm{E}(\mathrm{x})
$$

( $\mathrm{x}$ really exists iff $\mathrm{x}$ exists in a really possible world)

Definition 2: Modal ontic operators of real necessity and real possibility

These arise by restricting the range of accessible worlds under the condition of belonging to the set $Q$.

$$
\begin{aligned}
S \mid=_{\mathrm{u}} \square^{*} \alpha & \Leftrightarrow \forall \mathrm{v}\left(\mathrm{u} R \mathrm{v} \wedge \mathrm{v} \in Q \Rightarrow S||_{\mathrm{v}} \alpha\right) \\
& \Leftrightarrow(\forall \mathrm{v} \in Q)\left(S \mid={ }_{\mathrm{v}} \alpha\right)
\end{aligned}
$$

and 


$$
\begin{aligned}
S \mid=_{\mathrm{u}} \nabla^{*} \alpha & \Leftrightarrow \exists \mathrm{v}\left(\mathrm{u} R \mathrm{v} \wedge \mathrm{v} \in Q \wedge S \mid={ }_{\mathrm{v}} \alpha\right) \\
& \Leftrightarrow(\exists \mathrm{v} \in Q)\left(S \mid={ }_{\mathrm{v}} \alpha\right)
\end{aligned}
$$

Corollary 1:

$\square \alpha \Rightarrow \square^{*} \alpha \quad$ by def. of $\square$ and $\square^{*}$

but not:

$\diamond \alpha \Rightarrow \nabla^{*} \alpha$

by def. of $\square$ and $\square^{*}$

Definition 3: Analytically possible individuals

The above reflections on the notion of analytically possible world also apply to the notion of analytically possible entity. As analytically possible worlds are such only by virtue of their consistency, similarly analytically possible entities are such only by virtue of their consistency. But, a possible world is an analytically possible world. Therefore, $\mathrm{x}$ is analytically possible iff there is some possible world in which $\mathrm{x}$ exists. In formal terms:

$$
\begin{aligned}
\mathrm{P}(\mathrm{x}) & \Leftrightarrow \exists \mathrm{v}\left(S \mid={ }_{\mathrm{v}} \mathrm{E}(\mathrm{x})\right) \\
& \Leftrightarrow \diamond \mathrm{E}(\mathrm{x})
\end{aligned}
$$

( $\mathrm{x}$ is possible iff it is possible that $\mathrm{x}$ exists)

Corollary 2 (Main principle of ontological frame PS): Every possible is existent in some possible world. In formal terms:

$$
\begin{gathered}
\forall \mathrm{x} \exists \mathrm{v}\left(S \mid={ }_{\mathrm{v}} \mathrm{E}(\mathrm{x})\right) \\
\forall \mathrm{x} \oslash \mathrm{E}(\mathrm{x}))
\end{gathered}
$$

(for every $\mathrm{x}$ it is possible that $\mathrm{x}$ exists)

Proof:

$$
\begin{array}{ll}
\mathrm{P}(\mathrm{x}) \Leftrightarrow \exists \mathrm{v}\left(S \mid={ }_{\mathrm{v}} \mathrm{E}(\mathrm{x})\right) & \text { def. } \mathrm{P}(\mathrm{x}) \\
\forall \mathrm{xP}(\mathrm{x}) \Leftrightarrow \forall \mathrm{x} \exists \mathrm{v}\left(S \mid={ }_{\mathrm{v}} \mathrm{E}(\mathrm{x})\right) & \text { logic } \\
\forall \mathrm{xP}(\mathrm{x}) & \text { def. } W \\
\forall \mathrm{x} \exists \mathrm{v}\left(S \mid={ }_{\mathrm{v}} \mathrm{E}(\mathrm{x})\right) & \text { logic } \\
\forall \mathrm{x} \diamond \mathrm{E}(\mathrm{x}) & \text { def. } \diamond
\end{array}
$$

The above reflections on the notion of really possible world also apply to the notion of really possible entity. Just as the set of analytically possible worlds cannot be equated with that of really possible worlds, the 
set of analytically possible entities cannot be identified with that of really possible entities. This is due to the close relation between really possible world and really possible entity. So, as hereafter the notion of analytically possible entity has been introduced through that of analytically possible world, now the notion of really possible entity will be actually introduced through the notion of really possible world.

Definition 4: Really possible individuals

Given any possible world, all the analytically possible entities are present in it since all the consistently definable objects are analytically possible in every possible world. Note: we used the word 'present' - not 'existent' - since existence, in a world, does not necessarily pertain to all analytically possible entities but only to the entities that would really exist if the world in which they exist were actualised. These are, therefore, the possibilia that exist in that world. The really (and not just analytically) possible entities are the possibilia that exist at least in some really possible world.

$$
\begin{aligned}
\mathrm{RP}(\mathrm{x}) \Leftrightarrow & (\exists \mathrm{v} \in Q)\left(S \mid={ }_{\mathrm{v}} \mathrm{E}(\mathrm{x})\right) \\
& \Leftrightarrow \diamond \mathrm{E}^{\star}(\mathrm{x})
\end{aligned}
$$

( $\mathrm{x}$ is really possible iff it is really possible that $\mathrm{x}$ exists)

Corollary 3: $\mathrm{x}$ is really possible iff it is possible that $\mathrm{x}$ really exists.

$$
\begin{gathered}
\mathrm{RP}(\mathrm{x}) \Leftrightarrow \exists \mathrm{v}\left(S \mid={ }_{\mathrm{v}} \mathrm{E}^{*}(\mathrm{x})\right) \\
\mathrm{RP}(\mathrm{x}) \Leftrightarrow \Delta \mathrm{E}^{*}(\mathrm{x})
\end{gathered}
$$

Proof:

$$
\begin{aligned}
& \mathrm{RP}(\mathrm{x}) \Leftrightarrow(\exists \mathrm{v} \in Q)\left(S \mid=_{\mathrm{v}} \mathrm{E}(\mathrm{x})\right) \quad \text { def. } \mathrm{RP}(\mathrm{x}) \\
& \mathrm{RP}(\mathrm{x}) \Leftrightarrow \exists \mathrm{v}\left(\mathrm{v} \in Q \wedge S \mid={ }_{\mathrm{v}} \mathrm{E}(\mathrm{x})\right) \quad \text { logic } \\
& \mathrm{RP}(\mathrm{x}) \Leftrightarrow \exists \mathrm{v}\left(S\left|={ }_{\mathrm{v}} \mathrm{Q} \wedge S\right|={ }_{\mathrm{v}} \mathrm{E}(\mathrm{x})\right) \quad \text { def. } \mathrm{Q} \\
& \mathrm{RP}(\mathrm{x}) \Leftrightarrow \exists \mathrm{v}\left(S \mid={ }_{\mathrm{v}} \mathrm{Q} \wedge \mathrm{E}(\mathrm{x})\right) \quad \text { logic } \\
& \mathrm{RP}(\mathrm{x}) \Leftrightarrow \exists \mathrm{v}\left(S \mid={ }_{\mathrm{v}} \mathrm{E}^{\star}(\mathrm{x})\right) \quad \text { def. } \mathrm{E}^{\star} \\
& \mathrm{RP}(\mathrm{x}) \Leftrightarrow \diamond \mathrm{E}^{\star}(\mathrm{x}) \quad \text { def. } \diamond
\end{aligned}
$$

Definition 5: Purely analytically possible individuals

These are the analytically possible individuals that are not really possible. 


$$
\begin{aligned}
& \operatorname{PAP}(\mathrm{x}) \Leftrightarrow(\exists \mathrm{v})\left(\mathrm{S} \mid={ }_{\mathrm{v}} \mathrm{E}(\mathrm{x})\right) \wedge \neg(\exists \mathrm{v})\left(\mathrm{v} \in Q \wedge \mathrm{S} \mid={ }_{\mathrm{v}} \mathrm{E}(\mathrm{x})\right) \\
& \operatorname{PAP}(\mathrm{x}) \Leftrightarrow \diamond \mathrm{E}(\mathrm{x}) \wedge \neg \vee \mathrm{E}^{\star}(\mathrm{x})
\end{aligned}
$$

\subsection{Propositions on the ontological structure $S$}

There are many laws that characterize the ontological structure. Here, we are interested only in the most important for our discourse. They concern the necessity character the real predicates possess as rigid predicates and the splitting between the Kantian and Leibnizian models of ontological frame.

\subsubsection{Law of necessitation of the essential properties}

Let $\alpha(\mathrm{x})$ be an essential predicate (i.e. E do not occur in $\alpha$ ), then $\alpha(\mathrm{x}) \rightarrow \square \alpha(\mathrm{x})$.

This law finds its justification in the rigid character of the individual variables and of all essential predicates. Only the existence predicate is not rigid.

\subsubsection{Splitting between Kantian and Leibnizian interpretations of ontological frame $S$}

1. The Kantian model is characterized by the fact that:

$$
Q \neq W \quad \text { and then } \quad \operatorname{not}\left(\diamond \alpha \Rightarrow \diamond^{*} \alpha\right)
$$

Consequently:

$$
\operatorname{not}\left(\forall \mathrm{x} \diamond \mathrm{Ex} \Leftrightarrow \forall \mathrm{x} \diamond \mathrm{E}^{\star} \mathrm{x}\right)
$$

(The really possibles do not coincide with the analytically possibles)

2. On the contrary, the Leibnizian model is characterized by the identity:

$$
Q=W \quad \text { and then } \quad \nabla \alpha \Leftrightarrow \nabla^{*} \alpha
$$

Consequently, for Leibniz holds:

$$
\text { 1. } \forall \mathrm{x} \diamond \mathrm{Ex} \Leftrightarrow \forall \mathrm{x} \diamond \mathrm{E}^{*} \mathrm{x}
$$

(The really possibles coincide with the analytically possibles)

2. Principle PL: $\forall \mathrm{x} \diamond \mathrm{E}^{\star} \mathrm{x}$ (by the Main principle PS)

(Every possible can really exist)

Philosophically, the fact that there are models of the ontological structure in which not all analytical possibilia are existing in some real world is very important. It means that the analytical possibility of 
a concept is not a sufficient condition for that concept to be exemplifiable (actuable). To be precise, this element underlies the insurmountable component of the Kantian criticism of the modal ontological proof.

In fact, the aim of the second part of this paper is to analyse specifically this question in order to show that also the last version of ontological proof, Gödel's one, falls under the Kantian criticism of the purely analytical notion of possibility. We will consider, first, the Leibnizian formulation of modal proof and then Gödel's one. For both formulations we shall present only the relevant aspects from the Kantian versus Leibnizian point of view about possibility.

\section{THE ONTOLOGICAL ARGUMENT IN THE MODAL FORMULATION OF LEIBNIZ AND GÖDEL}

Leibniz's version of the ontological argument stands out for being endowed with modal structure. This is quite evident in all formulations Leibniz assigns to the argument along every step of his reasoning. The same is found, in a less developed fashion and with a few features of its own, also in Descartes' Meditation V. The advantage of the modal formulation of the argument is that the modal structure of it allows the narrowing down of all premises to one main premise, more precisely, the one stating the possibility of the maximally perfect Being.

\subsection{Leibniz's formulation of modal ontological proof $(1676,1701)$}

Leibniz's version of the ontological argument (see Leibniz 1676 and 1701) is based on two premises.

Descartes' Principle (PC):

1. $\forall \mathrm{x} \square\left(\mathrm{Gx} \wedge \mathrm{E}^{\star} \mathrm{x} \rightarrow \square\left(\mathrm{Gx} \wedge \mathrm{E}^{\star} \mathrm{x}\right)\right)$ (Strong Principle)

(if $x$ is $G$ and $x$ really exists then it is necessary that $x$ is $G$ and $x$ really exists)

2. $\forall \mathrm{x} \square(\mathrm{Gx} \rightarrow \square \mathrm{Gx})$ (Weak Principle)

(if $x$ is $G$ then it is necessary that $x$ is $G$ )

Main Premise: $\exists \mathrm{x} \diamond\left(\mathrm{Gx} \wedge \mathrm{E}^{\star} \mathrm{x}\right)$

(some really possible $\mathrm{x}$ is $\mathrm{G}$ )

To prove is: $\exists x\left(G x \wedge E^{\star} \mathrm{x}\right)$

(some $\mathrm{x}$ that is $\mathrm{G}$ really exists) 


\section{Proof:}

Part 1. Leibniz's Rule (LR) (where X is a set of formulas)

$$
\frac{\mathrm{X} \alpha \mid-\square \alpha}{\square(\mathrm{X}) \diamond \alpha \mid-\alpha}
$$

Derivation (in S5):

$$
\begin{array}{ll}
\mathrm{X} \alpha \mid-\square \alpha & \text { Hypothesis } \\
\mathrm{X} \neg \square \alpha \mid-\neg \alpha & \text { Contraposition } \\
\mathrm{X} \diamond \neg \alpha \mid-\neg \alpha & \text { Transf } \square \diamond \\
\square(\mathrm{X}) \square \diamond \neg \alpha \mid-\square \neg \alpha & \text { Necessitation } \\
\square(\mathrm{X}) \diamond \neg \alpha \mid-\square \neg \alpha & \text { by Axiom } 5 \\
\square(\mathrm{X}) \neg \square \neg \alpha \mid-\neg \diamond \neg \alpha & \text { Contraposition } \\
\square(\mathrm{X}) \diamond \alpha \mid-\square \alpha & \text { Transf } \square \diamond \\
\square(\mathrm{X}) \diamond \alpha \mid-\alpha & \text { by Axiom T }
\end{array}
$$

Part 2.

$\mathrm{Gx} \wedge \mathrm{E}^{\star} \mathrm{x} \rightarrow \square\left(\mathrm{Gx} \wedge \mathrm{E}^{\star} \mathrm{x}\right) \mathrm{Gx} \wedge \mathrm{E}^{\star} \mathrm{x}$

$$
\begin{aligned}
& 1-\square\left(\mathrm{Gx} \wedge \mathrm{E}^{\star} \mathrm{x}\right) \quad \text { A, MP } \\
& \square\left(\mathrm{Gx} \wedge \mathrm{E}^{\star} \mathrm{x} \rightarrow \square\left(\mathrm{Gx} \wedge \mathrm{E}^{*} \mathrm{x}\right)\right) \diamond\left(\mathrm{Gx} \wedge \mathrm{E}^{\star} \mathrm{x}\right) \\
& 1-G x \wedge E^{*} x \\
& \text { by LR } \\
& \forall \mathrm{x} \square\left(\mathrm{Gx} \wedge \mathrm{E}^{*} \mathrm{x} \rightarrow \square\left(\mathrm{Gx} \wedge \mathrm{E}^{*} \mathrm{x}\right)\right) \exists \mathrm{x} \oslash\left(\mathrm{Gx} \wedge \mathrm{E}^{*} \mathrm{x}\right) \\
& 1-\exists \mathrm{x}\left(\mathrm{Gx} \wedge \mathrm{E}^{\star} \mathrm{x}\right) \\
& \forall \mathrm{I}, \mathrm{I} \exists, \exists \mathrm{I} \\
& \exists \mathrm{x} \diamond\left(\mathrm{Gx} \wedge \mathrm{E}^{\star} \mathrm{x}\right) \mid-\exists \mathrm{x}\left(\mathrm{G} \mathrm{x} \wedge \mathrm{E}^{\star} \mathrm{x}\right) \\
& \text { by } \mathrm{PC} 1
\end{aligned}
$$

For Leibniz this principle is plausible since it is utterly befitting that the most perfect Entity, provided it does exist, be necessary. An entity that possesses perfections or existence contingently cannot be most perfect. Gödel too believes that necessary existence is a perfection. Note that the affirmation of the positivity of necessary existence is not axed even by the Kantian criticism. As a matter of fact, as for the existence, this criticism is justified for two reasons. Not only does the existence add nothing to 
the perfection of an object but neither does it indicate any perfection of the essence. All essences (the possibilia) are prone to existence; hence the fact that an essence is exemplified does not mean that this essence is more perfect than another. Neither does necessary existence add, of itself, any perfection to the essence of a thing. However, as it cannot be equally attributed to all essences, it is an indicator of greater perfection of the essences to which it is indeed attributed. In other words, not any essence may be endowed with necessary existence, but only that privileged one, which is essence able to exist necessarily. There is, then, a strong reason for considering necessary existence susceptible to evaluation. This does not mean, though, that necessary existence may be considered a perfection to the same extent as essential perfections. Indeed, as stated above, existence (hence necessary existence, too) belongs to a different modal level from the essential layer. What truly allows necessary existence to count as a highly plausible requisite for the maximally perfect Entity is that necessary existence is most certainly a more perfect form of existence than mere existence. Hence, the former is not assessed as such against essential properties, but against existence. Finally, viewing divine perfection not only in terms of its essential properties but - being existing - also in terms of its modality of being, its perfection requires necessary existence (with reference also to such a layer).

ad Main Premise: $\exists \mathrm{x} \diamond\left(\mathrm{Gx} \wedge \mathrm{E}^{\star} \mathrm{x}\right)$

Leibniz's attempt to justify the premise, as featured in his 1676 writing, consists of proving that pure perfections are compatible with one another, and to the extent that it is possible to postulate that the intersection of all perfections - that is, the maximally perfect Being, as the bearer of all perfections - is itself possible. In our language that means to obtain $\exists \mathrm{x} \diamond\left(\mathrm{Gx} \wedge \mathrm{E}^{\star} \mathrm{x}\right)$ (some really possible $\mathrm{x}$ is $\mathrm{G}$ ). The argument consists of two parts:

Part 1.

The starting point is the definition of positive absolute perfection:

"I call a perfection every simple quality which is positive and absolute, i.e. which expresses whatever it expresses without any limitations" (Leibniz 1676: 261)

Let $A, B, C$... be positive properties

Let $\mathrm{Gx}$ be $\mathrm{Ax} \wedge \mathrm{Bx} \wedge \mathrm{Cx} \ldots$

Let $\mathrm{F}(\mathrm{x})$ be a conjunction of a finite number of positive properties 
Then:

Cons $\mathrm{F}(\mathrm{x})$

by definition

In fact, from the above definition it can be easily derived that the perfections cannot be incompatible. As a matter of fact, since they are simple, they do not result from the composition of other perfections and, consequently, neither can they be the negation of any other. Therefore, the conjunction of any finite number of perfections is consistent. But, at this point, Leibniz's principle comes into play according to which every consistent property is exemplifiable, i.e. the principle stating that there is at least one possible in which that property inheres. In formal terms:

$$
\begin{aligned}
\text { Cons } \mathrm{F}(\mathrm{x}) \Rightarrow \exists \mathrm{xF}(\mathrm{x}) \quad & \text { because Consistency = satisfiability } \\
& =\text { analytical possibility }
\end{aligned}
$$

then:

$\exists \mathrm{xGx}$

by passage to infinity

Part 2.

At this point, to achieve $\exists \mathrm{x} \oslash\left(\mathrm{Gx} \wedge \mathrm{E}^{\star} \mathrm{x}\right)$ requires the use of Leibniz's axiom PL $\forall \mathrm{x} \oslash \mathrm{E}^{\star} \mathrm{x}$. In fact:

$\begin{array}{ll}G x E^{\star} x \mid-G x \wedge E^{*} x & \text { by Assumption } \\ \square G x \diamond E^{*} x \mid-\diamond\left(G x \wedge E^{*} x\right) & \text { Possibilitation } \\ \square G x \diamond E^{\star} x \mid-\exists x \diamond\left(G x \wedge E^{\star} x\right) & \text { I } \exists \\ \square G x \forall x \diamond E^{\star} x \mid-\exists x \diamond\left(G x \wedge E^{\star} x\right) & \forall I \\ \square G x \mid-\exists x \diamond\left(G x \wedge E^{*} x\right) & \text { by PL } \\ G x \mid-\exists x \diamond\left(G x \wedge E^{*} x\right) & \text { by PC2 } \\ \exists x G x \mid-\exists x \diamond\left(G x \wedge E^{\star} x\right) & \exists I\end{array}$

Leibniz's process contains two problem areas. The first concerns the passage to infinity dealt with at the end of Part 1. The second regards the use of Leibniz's principle PL on analytical possibility.

(1) The passage to infinity, which takes place at the end of the first part of the argument, is formally expressed by the following implication: if (for any F) $\exists x F x$ then $\exists x G x$. Now, this very implication is not guaranteed if the logic that regulates the relations between the concepts is not complete. It should be noted that the passage from the satisfiability of all finite subsets of an infinite set to the satisfiability of 
the latter is legitimate only if the theorem of semantic finiteness (or compactness) is valid. However, this theorem is not unconditionally valid; as a matter of fact, the theorem of semantic finiteness is guaranteed only by completeness.

(2) The second objection regards the use of Leibniz's principle, which is refuted by Kant. It is not guaranteed that from the analytical possibility of $G(\exists x G x)$ follows the real possibility of $G\left(\exists x \oslash\left(G x \wedge E^{\star} x\right)\right)$, unless the Leibnizian axiom on identity between analytical and real possibility has been accepted.

\subsection{Gödel's modified version of the ontological proof (1970)}

Gödel's version of the ontological proof is interesting because, compared to that of Leibniz, it is a new attempt to overcome the objection to Leibniz's unjustifiable passage to infinity. This objective is pursued by showing that the system of pure perfections has a principal ultrafilter structure. The objection to the passage is overcome under rather strong conditions. However, the proof is incapable of overcoming the second objection based on Kantian criticism. To show this, however, it is convenient to adapt Gödel's ontological proof to the semantics of the structure $S$. This forces us to make some changes, but allows two kinds of advantages:

(1) Firstly, in order to obtain the main premise of the proof, it is possible to use only part of Gödel's argument, reducing the number of the necessary axioms, i.e. to only three.

(2) Secondly, the semantics of the structure $S$ allows us to avoid some problems associated with Gödel's concept of existence. There are five important issues in this regard.

(a) Gödel's notion of perfection is independent, as Gödel says, from the accidental features of the world. This means that the extensional meaning of a property would have to be referred to sets of possible entities and not to sets of actual entities. In other words, the range of variables would be a domain of possible and not of actual individuals.

(b) As a consequence of point a, it is difficult to conceive of existence as an exemplification in some world. According to extensional interpretation, all the possibles are by definition exemplified in every world.

(c) If the entities are interpreted as possibles, the domain of possibles is the same in all the worlds. Therefore, a semantics based on 
a fixed domain is more appropriate than a semantics based on a variable domain.

(d) It is convenient to conceive the essential predicates of the individual possibles as rigid predicates, i.e. predicates that hold for the same individual in every world.

(e) Consequently, it is also convenient to introduce a new predicate of existence, as it is in the ontological frame $S$.

Therefore, Gödel's ontological proof may be presented in the semantic context of the structure $S$ enriched with the deontic component, i.e. in the ontological structure of the pure perfections SP. Gödel's proof is set out in two parts. The first part demonstrated the possible existence of a substance that, according to the definition provided, is God (similarly to the main premise). The second part demonstrated that God necessarily exists, based on the fact that maximum divine perfection requires divine existence to be necessary (similarly to principle PC). For our purpose, we shall consider only the first part as the other is already covered by Leibniz's formulation presented above. We follow Gödel in presenting the proof (although the numbers of the axioms differ) as for A1 and A2. As for A3, we keep to the formulation provided by Fitting (2002: 148), where A3 coincides with the Axiom 11.10. The reasons underlying this change will become clear later on.

\subsubsection{Extension of the language used to describe the ontological structure SP}

The language is extended in standard way to second order variables (for technical aspects see Fitting 2002, pp. 145-172). X, Y, Z, ... are predicative variables for properties (intensions) or sets (extensions) of possibilia. $\neg \mathrm{X}$ indicates the negation of $\mathrm{X}$ (intension) or the complement of $\mathrm{X}$ (extension). Similarly, the usual set theoretical operations are allowed.

$P$ is the first new sign for a third-order property. It is the sign of positivity (or any specific evaluation operator) concerning the essential properties of the elements of $U$, i.e. the sets corresponding to the properties of possible objects (according to the extensional interpretation). In Gödel's view, a property is positive when it represents a perfection. A perfect property is a property expressing unlimited value.

It should be noted that: 1 . Only real properties are susceptible of being positive. 2. Being possible is positive (compared to not being possible) but being actual (Ex) cannot be considered positive if compared to being possible; neither is the property of being necessary $(\mathrm{Ex} \rightarrow \square \mathrm{Ex})$ 
assessable through predicate $P$, since it is not a real property. 3. In Leibniz's wake, Gödel deems it appropriate to speak of the positivity of necessary existence rather than contingency. The positivity of necessary existence is determined through axiom 4, where the property $P$ is attributed directly to necessary existence. This seems to be justified in Gödel's language, in that it does not make any difference between existence properties and real properties. As pointed out above, though, this triggers a number of issues related to Gödel's semantics, which will be analysed shortly. 4 . The fact that necessary existence may not be the subject of assessment in terms of $\mathrm{P}$, does not imply that it is not a perfection with respect to simple existence, hence it does not justify the assumption of Descartes' principle PC. Indeed, in this particular instance the comparison takes place within the modality of being and not within the modality of essence or between the former and the latter. The reasons for that have already been explained.

$\mathrm{Z}$ is the second new sign for a third-order property. $\mathrm{Z}$ is a variable that designates any collection of properties. The following abbreviations may also be used (see Fitting 2002: 148):

(1) $\operatorname{pos}(\mathrm{Z}) \Leftrightarrow \forall \mathrm{X}(\mathrm{Z}(\mathrm{X}) \rightarrow \mathrm{P}(\mathrm{X}))$

(2) $\mathrm{X}$ intersection of $\mathrm{Z} \Leftrightarrow \square \forall \mathrm{x}(\mathrm{X}(\mathrm{x}) \leftrightarrow \forall \mathrm{Y}(\mathrm{Z}(\mathrm{Y}) \rightarrow \mathrm{Y}(\mathrm{x})))$

\subsubsection{Additional Axioms}

The ontological structure of perfections $S P$ is characterized, besides the other statements characteristic of structure $S$ and previously formalised, by the following three additional axioms:

Axiom 1: $\forall \mathrm{X}(\mathrm{P}(\mathrm{X}) \leftrightarrow \neg \mathrm{P}(\neg \mathrm{X}))$

(Exactly one of a property or its complement is positive)

Axiom 2: $\forall \mathrm{X} \forall \mathrm{Y}((\mathrm{P}(\mathrm{X}) \wedge \mathrm{X} \subset \mathrm{Y}) \rightarrow \mathrm{P}(\mathrm{Y}))$

(The properties entailed by positive properties are positive)

Axiom 3: $\forall \mathrm{Z}[$ pos $(\mathrm{Z}) \rightarrow \forall \mathrm{X}[(\mathrm{X}$ intersection of $\mathrm{Z}) \rightarrow \mathrm{P}(\mathrm{X})]]$

(The conjunction of any collection of positive properties is positive)

I am not interested in explaining the details of these axioms. I would like only to present some brief remarks about them.

The first axiom is true because contradictory perfections cannot be both positive and because either a property or its negation is positive. It should be noted that $\mathrm{X}$ can be not positive, not because it does not 
express value, but because the value it expresses has a constitutive limit: this is true, for instance, for the concept of human being. In this regard, it is also understandable why, conversely, not being a human being is positive. It is positive because it excludes the limit.

The second axiom is true because if $\mathrm{X} \subset \mathrm{Y}$ then being $\mathrm{Y}$ is a prerequisite for being $\mathrm{X}$, so if $\mathrm{X}$ is positive, $\mathrm{Y}$ must also be positive.

The third axiom is a generalization up to infinite of the principle stating that if two properties are positive their intersection is also positive. The importance of this principle will be illustrated below.

\subsubsection{Main Theorem: Consistency of the intersection of all perfections}

Let us define the concept of predicate $G$ as the intersection of all perfections:

$$
\mathrm{G}={ }_{\text {def }} \cap \mathrm{X}(\mathrm{PX})
$$

Then $\exists x G x$, because in virtue of $\mathrm{A} 1-\mathrm{A} 3 \cap \mathrm{X}(\mathrm{PX})$ is not empty.

The proof consists in showing that A1-A3 define on the set $\mathrm{U}$ of possibles a principal ultrafilter SP that guarantees the truth of $\exists \mathrm{xGx}$. SP, the system of pure perfections, includes the ultrafilter SP as a central core.

Proof:

SP is a filter in virtue of the following statements:

(1) $\mathrm{SP} \subseteq \wp(\mathrm{U})$

In fact, the perfections are subset of $U$.

(2) $\mathrm{X} \in \mathrm{SP}$ and $\mathrm{Y} \in \mathrm{SP} \Rightarrow \mathrm{X} \cap \mathrm{Y} \in \mathrm{SP}$

The proof is articulated in two parts: the first part shows that given two positive properties, their intersection is not void. The second shows that the intersection of any pair of positive properties is itself positive.

1. Part: if $\mathrm{X}$ and $\mathrm{Y}$ are positive then $\mathrm{X} \cap \mathrm{Y}$ is not empty

Given two positive properties $\mathrm{X}$ and $\mathrm{Y}$, only two cases are possible:

1. Case:

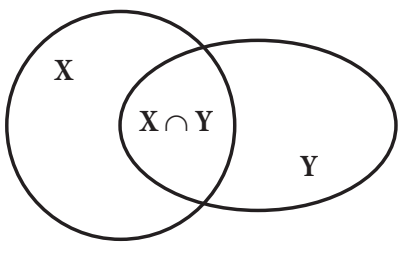


2.Case:

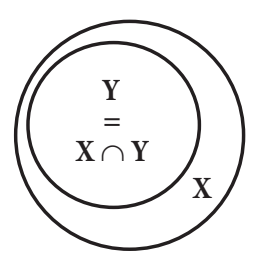

On the contrary the following case is excluded, where the intersection is empty:

3. Case:

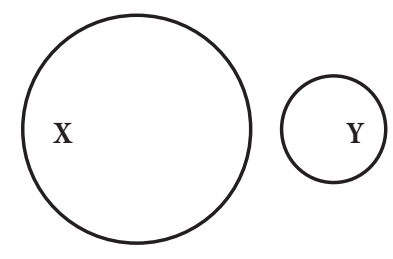

In fact:

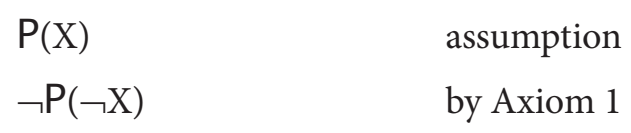

On the other side:

$\begin{array}{ll}\mathrm{P}(\mathrm{Y}) & \text { assumption } \\ \mathrm{Y} \subset \neg \mathrm{X} & \text { contradictory hypothesis } \\ \mathrm{P}(\neg \mathrm{X}) & \text { by Axiom } 2\end{array}$

Then:

$\mathrm{Y} \not \subset \neg \mathrm{X} \quad$ by refutation

Therefore, there exists a non empty intersection of every two positive properties.

2. Part: it follows from Axiom 3.

(3) $\mathrm{X} \in \mathrm{SP}$ and $\mathrm{X} \subseteq \mathrm{Y} \subseteq \mathrm{U} \Rightarrow \mathrm{Y} \in \mathrm{SP}$

Proof: it follows from Axiom 2. 
Moreover, SP is a proper filter, because $\varnothing$ is not a positive property: the proof that follows from Axiom 1 ad Axiom 2 is well known (see Fitting 2002, pp. 147-148).

SP is an ultrafilter because holds:

(4) $\mathrm{X} \in \mathrm{SP}$ or $\neg \mathrm{X} \in \mathrm{SP}$ (SP is maximal)

Proof: it follows from Axiom 1.

(5) Finally, SP is a principal ultrafilter.

The demonstration follows from A3. The intersection of all perfections is therefore positive. But positive properties cannot be empty. Therefore, the generator of the ultrafilter exists. This coincides with the singleton of the entity characterized by all perfections.

Remark: Gödel's original system contains, instead of $\mathrm{A} 3$, the weaker axiom $\forall \mathrm{X} \forall \mathrm{Y}([\mathrm{P}(\mathrm{X}) \wedge \mathrm{P}(\mathrm{Y})] \rightarrow \mathrm{P}(\mathrm{X} \wedge \mathrm{Y})$ ) (If two properties are positive, their combination is also positive). However, this axiom is not sufficient to ensure the derivation of $\exists x G x$. As stated by Szatkowski (2005: 319), a system of axioms such as A1-A2 + Gödel's axiom, which was just mentioned in place of $\mathrm{A} 3$, could be interpreted on a non-principal ultrafilter containing all co-finite subsets of U. In such an ultrafilter, the proposition $\exists \mathrm{xGx}$ would be false since in it the intersection of all co-finite sets is empty. It is therefore necessary to reinforce the system with an axiom such as A3 (corresponding to Fitting's 11.10 axiom). An alternative axiom to this could be the assertion of the positivity of $\mathrm{G}$ (which is equivalent to A3, as shown by Fitting 2002: 153), an axiom that was also proposed by D. Scott in place of the original one (see Sobel 2004: 145). Of course, the reinforcement of the third axiom diminished the meaning of Gödel's proof. In fact, the meaning of a proof is determined by the greater accessibility of the axioms compared to the conclusion and, in our case, there is hardly any difference between the effort to reach the axiom and the effort to reach the conclusion, which is not far from circularity. In the context of these reflections, in order to guarantee the principal character of the ultrafilter and, consequently, to ensure the truth of the conclusion, it could be useful to require the presence of at least one finite positive property. It is well known, in fact, that the principality of an ultrafilter is equivalent to the existence of at least one finite subset of the ultrafilter domain (see Bell Machover 1977: 140). This would mean that at least some perfections could not be shared by an infinite number of subjects. In this case, the perfection 
would lie in the exclusivity of the attribution, of which unicity would be the highest expression. Hence, to assume axiomatically that a positive property owned by a single subject exists would imply that that subject owns them all. After all, the property of being One is traditionally one of the divine attributes and, therefore, its being positive appears highly plausible. In conclusion, an axiom stating that being One is a perfection or, in general, an axiom stating the existence of a perfection which can be shared only by a finite number of subjects would have a greater founding meaning than the axiom of divine perfection or equivalents.

\section{CONCLUSIONS}

(1) Within the scope of the ontological structure $S$, axioms A1, A2 and A3 (with the emendation of the third axiom) provide that the system of perfections SP contains a principal ultrafilter. Not only does this mean that the intersection of any two (hence $n$ ) perfections does exist, but also that the intersection of all perfections, that is $\cap \mathrm{X}(\mathrm{PX})$, in virtue of the infinite passage (being perfections infinite), also exists. Now, it should be noted that this passage is entirely sound. As a matter of fact the model that satisfies the existence of non-empty intersections of any two (or a finite number of) perfections is the same that satisfies the existence of the intersection of all perfections. No property of compactness should be resorted to.

We have not obtained:

(for every finite set $F$ of perfections) (there exists a model $M$ of $F$ such that) [ $M$ satisfies $F]$, but

(there exists a model (being, roughly speaking, the principal ultrafilter $S P$ ) such that (for every finite or infinite set $A$ of perfections) [ $S P$ satisfies $A$ ],

hence the aforementioned result.

Despite the severe limitations of the abovementioned observations, Gödel's proof allows for the first flaw of the Leibnizian proof to be overcome.

(2) Gödel's proof, too, features the second problem to Leibniz's proof: $\exists \mathrm{x} \diamond\left(\mathrm{Gx} \wedge \mathrm{E}^{*} \mathrm{x}\right)$, does not follow from $\exists \mathrm{xGx}$ unless one accepts Leibniz's principle about the reality of analytically possibilia PL. 
In conclusion, Gödel's proof, too, is affected by the same basic flaw that was detected in Leibniz's proof. There is no guarantee that the analytical possibility is a real possibility.

\section{Final Critical Remarks}

Remark 1: The manuscript left by Gödel features two other axioms. These are instrumental for the second part of the proof, that is, proving Descartes' Principle PC. Indeed, one states that perfections are rigid; the other that necessary existence is positive. However the second one is problematic for the above mentioned reasons.

Remark 2: As has already been mentioned before, the language used to formulate our version of Gödel's ontological proof is similar to that used by Fitting (2002; see also Hájek 2002b). As within our language, and in Fitting's too, the quantification is construed in a possibilistic way; that is, the domain of quantifiers is the set of possibles and actual existence is expressed by existence predicate E. For instance, the expression $\exists x P x$ states that a possible object is characterized by property $\mathrm{P}$, whilst if we want to affirm that this object is actually existing, then it is necessary to also attribute the existence predicate $\mathrm{E}$ to it. In an analogous manner, the objectual domain is fixed and the existence predicate defines the extensions of existent objects in each possible world. It would be fair to assume that according to Fitting too, the properties that may be evaluated from the standpoint of their perfection were essential properties; that is, the properties rigidly defined in an extensional manner on the set of possible - and not of existent - beings. On the other hand, that does not appear to stem from Fitting's formulation (which can be found in Hájek's work, too) of Axiom 2: $\forall \mathrm{X} \forall \mathrm{Y}((\mathrm{P}(\mathrm{X}) \wedge \square \forall \mathrm{x}(\mathrm{Ex} \rightarrow(\mathrm{X}(\mathrm{x}) \rightarrow \mathrm{Y}(\mathrm{x}))))$ $\rightarrow \mathrm{P}(\mathrm{Y})$ ) (Axiom 11.5), where the inclusion relation among positive properties is restricted to the respective extensions defined on the set of existent beings. This, though, implies unacceptable consequences, as it will be clear in the following two remarks.

Remark 3: The analogous of Fitting's Axiom 11.5 in our language is $\forall \mathrm{X} \forall \mathrm{Y}\left(\left(\mathrm{P}(\mathrm{X}) \wedge \square \forall \mathrm{x}\left(\mathrm{E}^{\star} \mathrm{x} \rightarrow(\mathrm{X}(\mathrm{x}) \rightarrow \mathrm{Y}(\mathrm{x}))\right)\right) \rightarrow \mathrm{P}(\mathrm{Y})\right)$. Nevertheless such rewording deprives the axiom of all its plausibility, since the logic of real existence does not obey any deontic principle. It is possible, then, that among the existing beings of all really possible worlds there be inclusion relations that are not compatible with the logic of perfections. For the sake of argument, it would be fair to postulate that in all really possible 
worlds every existing honest individual is an existing farmer. Hence, being a farmer would be a pure perfection, which is absurd.

Remark 4: The above note voids Fitting's proof of Gödel's theorem 1 (translated into our language, $\mathrm{P}(\mathrm{X}) \mid-\diamond \exists \mathrm{x}\left(\mathrm{E}^{\star} \mathrm{x} \wedge \mathrm{X}(\mathrm{x})\right.$ )) of all pertinence. It may be easy to note that this theorem is obtained in Fitting (2002: 147), by virtue of Axiom 11.5 in Fitting's wording disputed above.

\section{BIBLIOGRAPHY}

Adams, R.M. 1971. 'The Logical Structure of Anselm's Argument', Philosophical Review, 80: 28-54

Anderson, A.C. 1990. 'Some Emendations of Gödel's Ontological Proof', Faith and Philosophy, 7: 291-303

Anderson, A.C., and M. Gettings. 1996. 'Gödel's ontological proof revisited', in P. Hájek (ed.), Gödel '96 Logical Foundations of Mathematics, Computer Science and Physics - Kurt Gödel Legacy (Berlin: Springer Verlag), Lecture Notes in Logic, 6, pp. 167-172

Bell, J.L., and M. Machover. 1977. A Course in Mathematical Logic (Amsterdam: North-Holland Publishing Company), Chapter 4, 'Boolean Algebras', pp. 125-160

Czermak, J. 2002. 'Abriß des ontologischen Argumentes', in B. Buldt et al (eds), Kurt Gödel. Wahrheit \& Beweisbarkeit, vol. 2, Kompendium zum Werk (Wien: VerlagsgmbH \& Co. KG), pp. 307-324

Fitting, M. 2002. Types, Tableaus, and Gödel's God (Dordrecht: Kluwer)

Fitting, M., and R. Mendelsohn. 1998. First Order Modal Logic (Dordrecht: Kluwer) Galvan, S. 1989. 'Una variante deontica dell'argomento modale di S. Anselmo', Epistemologia, 12, special issue, Logica e ontologia: 135-144

Galvan, S. 1993. 'Aspetti problematici dell'argomento modale di Anselmo', Rivista di Storia della Filosofia, 48: 587-609

Getting, M. 1999. 'Gödel's Ontological Argument. A Reply to Oppy', Analysis, 59: 309-313

Gödel, K. 1995. Collected Works, Vol. 3, S. Feferman et al (eds) (Oxford: Oxford University Press)

Hájek, P. 1996. 'Magari and others on Gödel's ontological proof', in A. Ursini e P. Aglianò (eds), Logic and Algebra (New York: Dekker), pp. 125-35

Hájek, P. 2002a. 'Der Mathematiker und die Frage der Existenz Gottes (betreffend Gödels ontologischen Beweis)', in B. Buldt et al (eds), Kurt Gödel. Wahrheit \& Beweisbarkeit, Vol. 2, Kompendium zum Werk (Wien: VerlagsgmbH \& Co. KG), pp. 325-336

Hájek, P. 2002b. 'A new emendation of Gödel's Ontological Proof', Studia Logica, 71: $149-164$ 
Hartshorne, C. 1965. Anselm's Discovery. A Re-Examination of the Ontological Prooffor God's Existence (LaSalle, IL: Open Court)

Hartshorne, C. 1962. The Logic of Perfection and other Essays in Neoclassical Metaphysics (LaSalle, IL: Open Court)

Kovac, S. 2003. 'Some Weakened Gödelian Ontological Systems', Journal of Philosophical Logic, 32: 565-588

Kutschera, F. v. 1991. Vernunft und Glaube (Berlin - New York: De Gruyter)

Leibniz, G.W. 1671. 'Quod Ens perfectissimum existit', in C.I. Gerhardt (ed.), Die Philosophischen Schriflen von Gottfried Wilhelm Leibniz (Hildesheim: Georg Olms Verlagsbuchhandlung, 1961), VII, pp. 261-62

Leibniz, G.W. 1701. 'Ohne Überschrift, enthaltend ein Schreiben Leibnizens in Betreff des Beweises für die Existenz Gottes von Benedictiner Lamy', in C.I. Gerhardt (ed.), Die Philosophischen Schriften von Gottfried Wilhelm Leibniz (Hildesheim: Georg Olms Verlagsbuchhandlung, 1960), IV, pp. 405-06

Lenzen, W. 1990. Leibnizens ontologischer Gottesbeweis und das Problem der unmöglichen Dinge, in: AA.VV., Mathesis rationis. Festschrift für Heinrich Schepers (Münster: Nodus Publikationen), pp. 285-300

Lenzen, W. 1990. Das System der Leibniz'schen Logik (Berlin: De Gruyter)

Löffler W. 2000. Notwendigkeit, S5 und Gott. Das Ontologische Argument für die Existenz Gottes in der Zeitgenössischen Modallogik (Münster: LIT Verlag)

Lowe, E. 2007. 'The Ontological Argument', in C. Meister and P. Copan (eds), The Routledge Companion to Philosophy of Religion (London: Routledge), pp. 331-340

Maydole, R. 2003. 'The Modal Perfection Argument for the Existence of a Supreme Being', Philo, 6: 299-313

Meixner, U. 1992. 'Der ontologische Gottesbeweis in der Perspektive der Analythischen Philosophie', Theologie und Philosophie, 67: 246-262

Morscher, E. 1994. 'Anselms Gottesbeweis und was Uwe Meixner daraus gemacht hat', Theologie und Philosophie, 69: 22-33

Muck, O. 1992. 'Eigenschaften Gottes im Licht des Gödelschen Arguments', Theologie und Philosophie, 67: 60-85

Oppy, G. 1996. 'Gödelian Ontological Arguments', Analysis, 56: 226-230

Oppy, G. 2006. Arguing about Gods (Cambridge: Cambridge University Press)

Sobel, J.H. 1987. 'Gödel's Ontological Proof', in J. J. Thomson (ed.), On Being and Saying, Essays for Richard Cartwright (Cambridge, MA: MIT press), pp. 241-261

Sobel, J.H. 2004. Logic and Theism. Arguments for and Against Belief in God (New York: Cambridge University Press)

Szatkowski, M. 2005. 'Semantic Analysis of some Variants of Anderson-like Ontological Proofs', Studia Logica, 79: 317-355

Szatkowski, M. 2011. 'Partly free semantics for some Anderson-like ontological proofs', Journal of Logic, Language and Information, 20: 475-512 